\title{
The Value of Inventory Accuracy in Supply Chain Management - Case Study of the Yedioth Communication Press
}

\author{
Hila Shteren ${ }^{1}$, Assaf Avrahami ${ }^{2}$ \\ 1 Ort Braude College, Faculty of Industrial Engineering, Karmiel, Israel, hila-tr@yedioth.co.il \\ 2 Technion-Israel Institute of Technology, Faculty of Industrial Engineering, Haifa, Israel, assaf@paymaxs.com \\ Received 7 December 2015; received in revised form 19 November 2016; accepted 20 December 2016
}

\section{Abstract}

Our work focuses on the quality information aspect of the inventory management domain of the supply chain in the organization.

Within the scope of quality information we have concentrated upon the discrepancies known as inventory errors, which are the result of events that can be classified as one of the following three types: Shrinkage, Misplacement and Wrong Scanning [1]. These events lead to differences between inventory reflected in the IT system records and available inventory for sale. These discrepancies and/or their associated negative effects can be minimized should additional information be available.

Our work explores four different models that operationally take the discrepancies into consideration in four different scenarios: (1) No Information Scenario, (2) Static Informed Scenario, (3) Informed Scenario, and (4) Full Information Scenario. The objective of our work is to explore and quantify the value of the additional information in Scenarios 2 - 4 compared to the No Information Scenario. We implemented an analytical mode for each scenario, where the objective in all four scenarios is to minimize the average expected cost per period.

Our findings indicate that additional information greatly influences optimal policies and, if exploited wisely, can save a great deal of money.

Keywords: Value of information, Inventory management, Supply chain, Inventory errors, Ecommerce. 


\section{Introducción}

This research relates to the quality of information and deals with discrepancies that result in inventory errors that arise from three different sources: Inventory shrinkage, Misplacement and Wrong Scanning. Inventory shrinkage is an inventory error that is defined as an event that changes the actual inventory, but does not affect the IT (Information Technology) inventory (breakage or theft are two typical examples). Placement of an item in the wrong place (misplacing) is an inventory error that decreases the available inventory (the actual inventory is unchanged, the item is still physically present, just in the wrong place). This error does not affect the IT inventory since this information system reflects items that have been misplaced. Wrong scanning of an item constitutes an inventory error that results in a decrease in the quantity of the said item appearing into the IT inventory without a change in the actual inventory and in the available inventory. Wrong scanning (which can also occur when an item enters the storeroom/an order is received as well as when an item leaves the storeroom/an order is filled) of an item affects two items: the item that is handled is added to/removed from the actual inventory without being reported to the IT system (so that it is considered as shrinkage) and the item that is reported to the IT system yet has not been handled. There is no impact on the available inventory but it may decrease or enlarge the IT inventory.

The result of these errors is a gap between the inventory level as it appears in the organization's inventory systems (the inventory as it appears in the organization's computerized systems) and the real inventory available for sale. The classic literature does not differentiate between the errors presented above, and only recently has the literature begun focusing on documenting inventory discrepancies. [8] Found that $65 \%$ of the inventory entries in a certain retailer were erroneous. In addition, [10] identified the total gap between the IT inventory and the actual inventory in the basic fashion industry and analyzed it.

The objective of our work is to explore and quantify the value of the additional information in different information based scenarios.

The context of this paper is the fact that the print industry is suffering from deep recession and has to cut operational costs. One of the most significant costs in this industry are raw materials and inventory management optimization. This industry as we will present later on in this paper has inventory errors that might cause extra costs.

Accurate information is necessary for e-commerce, with some information already exists in the organization's information technology system in this stage we need to maximize the quality of inventory management information to build a strategy for better integration between these systems.

Ecommerce is a nickname for trading and execution of transactions trading electronically via computer communication. Electronic commerce describes a wide range of activities on the Internet or private networks between groups. These activities include the dissemination of information by vendors, buying and selling activities of durable goods and services, customer support etc'.

In recent years, print journalism has found itself battling continual and increasingly strong competition from the Internet and the multitude of television channels. This competition is forcing printing houses to streamline their operations in order to maintain company profits. Accordingly, proficient management is a crucial element in the printing sector in general and in organization in particular. To this end, engineering tools can constitute key factors in efficient, economic and successful management toward realizing savings in costs, improved performance and increased profits.

The focus of business organization management is on optimizing supply chain management (SCM). SCM involves, among other efforts, managing the uncertainty and risks that exist in the process and stem from the fact that demand is generally nondeterministic and often is dynamic and dependent on statistical data.

Managing the supply chain in the best possible way is contingent on managing the data that exists in the system. Correct use of this information-to the extent possible- improves system performance and facilitates better results.

The fact that information has great value in SCM is known and acknowledged in the SCM literature. The value lies in two aspects of the information available in the supply chain: the quality and quantity of the information supporting supply chain decision making.

In terms of the cost components of printing, a significant factor contributing to higher costs has been identified: the cost of inventory arising from discrepancies between the different types of inventory [9] examined in the present research.

- IT inventory entries: The amount of inventory listed in the organization's information technology system

- Available inventory: The inventory available to be used 
- Actual inventory: The inventory that is physically present in the system (including all the available-for-use inventory that is in its proper location and the inventory that is not in its proper location and not available for use).

Each source creates a gap between the data in the IT system and the available inventory, albeit each affects the gap differently and diminishes the quality of the information differently. Conducting an inventory review serves to identify and eliminate these gaps.

Every business in which a running inventory of raw materials and products is maintained conducts an inventory review. Even though in modern businesses, where inventory is managed through IT systems that are supposed to provide exact information about the quantity of items in the inventory, inventory reviews are conducted. This usually means that the company's employees (generally, supervised by an accountant) physically count the individual items one by one.

We make sense of the discrepancies presented above using four different scenarios as presented in [1], [2]: (1) No Information; (2) Informed; (3) Informed Static; and (4) Full Information.

Each scenario has different costs. Each cost calculation is based on versions of the newsvendor problem. Each scenario requires a different quantity of information. The key to the study is the value of this information, which has a different cost in the scenario with less information than the scenario with more information. Intuitively, the anticipated cost in period $\mathrm{n}$ increases with $\mathrm{n}$. This is indeed true in the Informed Scenario because the uncertainty grows over time. Moreover, this is also true for the Static Informed Scenario for the same reason and because the inventory manager does not comprehend all the existing uncertainty. Likewise, we can also relate this to the No Information Scenario for the same reasons and because the expected value of the discrepancy grows over time. In contrast, the expected cost in the Full Information Scenario does not grow over time; it is static.

We conducted our research in the Yedioth Communication printing offices, which is a subsidiary of the Yedioth Aharonot Group. The Yedioth Aharonot Group is a private corporation whose shares are not sold on the stock exchange. The group is controlled privately.

Four different models dealing with inventory discrepancies were examined. The value of the discrepancy between the IT system inventory and the available-for-sale inventory in the print industry was studied and quantified. The theory and scope of errors in the print industry and their effect on inventory management was examined as well as the quantity ordered and the anticipated cost as a result of this. An examination of these parameters in regard to the print industry is unique, and accordingly, represents the innovativeness of the present research.

Previous researchers have identified these gaps in various industries, for example, [10] have identified these gaps in the basic clothing fashion industry and analyzed them. In our study we examine the sources of error that presented earlier in the printing industry.

It is a one-time study that examined data from the years 2010 to 2013 at printing press of Yedioth Communication Ltd a subsidiary of the Yedioth Aharonot media group. In the future we plan to continue the study at another printing house to examine the results to allow reasonable inference.

The rest of the paper is organized as follows. In Section 2 we review the relevant literature. In Section 3 we describe the present state of affairs. In Section 4 we propose solution approaches and present in detail the stages of the solution and the data that were collected and processed in accordance to the model's requirements, as well as present the model and how it is applied. In Section 5, the results of the simulation model that was applied to the main print auxiliary and raw materials are presented. Likewise, the recommendation is made regarding the optimal information scenario (inventory policy) to be followed for operating and managing the inventory at the printing house. In Chapter 6, a summary, conclusions and recommendations for further research are presented.

\section{Literature Review}

In this section we present a survey of the literature relevant to our work, the value of information in supply chain management (SCM).

The value of information in SCM has been discussed in previous work. [14] Presented a model that quantifies the value of information created by different levels of periodic inventory reviews. The paper compares two levels of inventory reviews and the effect of each one on the system's performance. They related to the case of a perfect inventory review, i.e., there are no errors remaining in the inventory entries after the previous review to calculate the optimal time interval between counts. Subsequently, the authors examined the degree of precision of the count that is justified economically while broadening the approach to studying the balance between the order of magnitude of errors that remain after the previous review and the cost of the review. 
[15] Investigated empirical information about the characteristics of errors when monitoring inventory entries. They examined the inaccuracy distribution as well as its size.

Work on information sharing relates to the value of information from a different perspective. [21] Presented analytical and numerical models that examined the value of information sharing among retailers and suppliers in their upstream. They presented a simple supply chain with two levels and uncertain demand. Their analyses indicated that the value of sharing data related to demand may be reasonably high. The analyses show that sharing data alone can lead to a significant decrease in inventory and savings in costs for the manufacturer. With these savings, the retailer can negotiate with the manufacturer, regarding, for example, use of supplier inventory systems to reduce the retailer's overhead and processing costs, reduce the price in order reduce the retailer's varying costs or reduce the lead time in order to reduce the retailer's inventory costs, prior to pooling sales data. Likewise, our analytical and numerical examples indicate that the basic demand process and the lead time have a significant effect on cost savings and inventory reduction linked to data sharing. Specifically, the findings show that the manufacturer will realize savings when: (a) the demand correlation over the long term is high; (b) the variation in demand in each time period is high; or (c) lead times are long.

[11] Examined the link between inventory inaccuracy and performance in the retailer supply chain. They imagined a supply chain with three links and one product, whose end customer's demand changes among the links. In the basic model, without alignment between the physical inventory and the inventory data system, the inventory data becomes inaccurate due to the poor quality of the process, theft, and items that become unsellable. In the second model, these factors that lead to inaccuracy are still presented but the physical inventory and the inventory data system are aligned at the end of each period. The results indicate that eliminating the inventory inaccuracy may reduce supply chain costs, as well as the level of actual inventory, Auto-ID technologies may be one of the means by which to achieve inventory accuracy.

[22] Looked at the impact of RFID (Radio-frequency identification) technology-at that time quite an innovation-on a generic supply chain. They developed a simulation model that presents the effect of the technology on a manufacturer-retailer supply chain. Their paper quantified the potential advantages of RFID technology and modeled a simply consumer goods manufacturer-retailer supply chain. They analyzed the impact of RFID technology on the dynamic and stochastic behavior of the supply chain. Their paper proposed two simulations of the model, one with and one without RFID technology. The three levels of the supply chain in their simulation comprised a manufacturer, a distribution center (DC) belonging to the manufacturer, and the retailer's store. For the retailer's store, they modeled four products that customers purchase with equal probability. Customers arrive according to a normal log distribution and the assumption is that the quantity of their purchases at every opportunity is uniformly distributed. Inventory is restocked in the store using $(\mathrm{S}, \mathrm{S})$ policies. Inventory on the shelf is restocked also according to (S,s) policies. The researchers assumed that a physical inventory review is done once every three months. The assumption is that product shrinkage in the retail store is uniformly distributed and amounts to $1.6 \%$, occurring both on the shelf and in the backroom. For the manufacturer they assumed that there were daily shipments to the DC. They set up a number of production policies. Lead time for a shipment from the manufacturer to the DC is one day. For the DC, the products are drawn from the retailer based on the retailer's restocking policy and frequency. Lead time for delivery from the DC to the retailer is one day. The results of the researchers' work show that the level of inventory in the process dropped $23-26 \%$ in a system using RFID technology.

[8] investigated the inaccuracies in inventory entries within and on the surface of product categories and retailers showed that $65 \%$ of their inventory entries were inexact (about 370,000 entries in 37 stores of one retailer were checked). In other words, the quantity of one item listed in the inventory did not match the amount found in the store. The researchers identified a number of factors that may lead to inaccuracies in entries such as item cost, amount sold, and inventory control performance, as well as a number of factors that exacerbate the inventory entry inaccuracies such as the complexity of the store environment and distribution structure.

[10] Related to an intelligent inventory management tool that calculates the inaccuracy in inventory entries using the physical inventory level. They assumed that in addition to the visible demand, there is also an invisible demand that causes errors. They showed that the probability distribution of the level of the physical inventory is the aggregate of past sales and anticipated inventory restocking. They demonstrated the use of this distribution as the basis for practical restocking of inventory and inventory review, and illustrated how the necessary parameters can be estimated using information from one large national retailer. The goal of a restocking policy is to prevent the problem of freezing, in which the physical inventory is zero while at the same time the inventory entry is positive. In addition, simulation studies show that this inventory restocking policy will return a lot of the cost of inaccurate inventory entries and that the performance of this inventory control policy is significantly higher than the popular zero-balance walk control policy.

[23] Investigated the use of RFID technologies from the production perspective. They applied this technology in a discrete production system with the objective of controlling the production process in real-time in order to improve its efficiency and quality. They compared the cost of control on the production floor and the raw materials using RFID technology and without such technology, and concluded that implementing RFID technology can save $20-30 \%$ of the overall costs of production process control. 
[1] Presented models intended to estimate the value of the information related to the gap between inventory entries in the system and the physical inventory. They analyzed three different sources of gaps: shrinkage, misplacement and transaction errors. As a result of these factors, the levels of actual inventory are not known with certainty. Consequently, the system cannot order when there is an actual need or else it carries more inventory than is necessary. Inventory errors accumulate until an inventory review is conducted. Periodic inventory review is the most widespread approach to maintaining accurate inventory entries. Following the inventory review, the inventory entries match the physical inventory, errors have been corrected and all items that were not in their place have been returned to the proper place. In the paper, the researchers took into consideration the final horizon, a single item, and a periodic inventory control system in which inventory entries are not accurate. They showed how different sources of errors lead to inaccuracy in inventory records. They determined an efficient restocking policy that uses information about actual inventory movement, error sources, and minimization of the total expected inventory costs. Following this, they determined a restocking policy that calculates the inventory inaccuracies without full transparency of the inventory and the source of errors. By comparing the overall cost of these two policies, they quantified the real value of inventory transparency, as well as the value of elimination or reduction of sources of inaccuracies between actual inventory and inventory lists by new tracking technologies such as RFID.

[12] Presented analytical models that evaluate the benefits of RFID for partners in a supply chain with one manufacturer and one retailer. They presented an analytical model with the benefits of RFID on the level of one item for the two partners in the supply chain. They checked two cases, one when the manufacturer is in charge and one when the retailer is in charge. Likewise, they assumed that the entrance of RFID technology on the level of the item in the supply chain depends on the market forces' characteristics noted above. For each scenario they presented how the cost of RFID on the level of the item must be divided among partners in the supply chain so that the supply chain profit is optimal.

[20] Summarized the power of RFID technology and its impact on all parts of the supply chain. Their paper related to the cost of work, direct improvement (for the supplier), inventory accuracy and inventory level.

[16] Related to one cumulative error (negative or positive) and developed a joint test (control) and an inventory replenishment policy that minimizes the total costs for the finite horizon. They proposed a periodic review policy (when to count inventory for control purposes) and quantified the value of exact inventory data, provided by RFID systems. In their paper, they assumed a basic inventory policy.

[18] Investigated the effect of RFID implementation in the case of shrinkage. By comparing the situation with RFID to the situation without it, in terms of costs, they derived a precise analytical expression for the price balance of an RFID tag. They performed an analysis based on an experiment that related to the value of items that get lost relative to the (unit) shrinkage and the shrinkage remainders that are left after RFID implementation.

[9] Presented a number of retailers and stressed an additional factor that affects the area of operations management, poor performance or inability to implement an operations program. They described the impact of poor performance on inaccuracy in inventory entries. It was found that despite implementation of algorithms for selecting the appropriate quantity of inventory and range in stores to hold, retail customers may still confront surplus sales inventory. Imprecise inventory entries and products that are not in their designated places are two examples of weak performance in stores. These problems affect the availability of products in two ways. First, they lead to sales inventory, and therefore, they compromise the level of retailer service. When the level of actual inventory of a certain item is lower than the planned level, as a result of inaccurate entries or misplacement of a product, the level of actual service will be lower than the planned level of service. Second, for retailers that rely on automatic inventory replenishment systems in order to manage inventory in the store, performance problems will impact the availability of a product in the future as a result of historical skewing of sales and inventory data stored in these systems. Skewing of inventory data may prevent issuing of a replenishment order because the inventory in the system will be larger than the actual inventory or may unnecessarily lead to inventory replenishment because the inventory in the system is lower than it actually is. Moreover, when the product, which is in fact no longer in the inventory, is reported to still exist in the inventory, the automatic inventory replenishment system may wrongly understand that that there is no demand for this product. The system shows that there are no sales of this item because, in reality, the item is not available to customers to purchase. Thus, even when a large number of customers want to buy the item, the system may automatically reduce the forecasted demand, which will cause the retailer to reduce the inventory or even remove the item from its stock totally. The poor performance factor affects the SC and acerbates it, if one uses an analytically optimal order quantity and advanced applications. Use of algorithms in order to determine the best quantities is not sufficient in order to prevent lack or oversupply. The researchers presented a study in which inventory errors were measured among retailers, and integrated the problems into the existing inventory models.

[13] Investigated the economic impact of inaccuracies in inventory entries arising from performance errors. They defined opportunities for correction that can be used in order to prevent inaccuracies (such as use of RFID technologies) or to correct inventory entries (e.g., advanced control policies). They used a model that simulated an inventory control system $(Q, r)$ in order to evaluate the economic effect of inaccuracies on inventory entries and compared the performance of the system with perfect inventory data to a system with performance errors. 
[6] Proposed an innovative approach in order to analyze the potential advantages of RFID systems. They suggested a distribution strategy for RFID technology that would determine their optimal position within a supply chain network. The resulting models can be used in evaluating information in relation to item losses.

[2] Investigated two aspects of information in a supply chain: the quality of information supporting decision making in a supply chain and the quantity of information supporting decision making in a supply chain. He dealt with the gaps that cause three types of inventory errors: inventory shrinkage (theft or damage to a product as a result of total destruction), item misplacement (as a result of stockroom error or because a customer unintentionally moved the item and placed it in the wrong location), wrong scanning of an item (as a result of stockroom error as the item enters the retailer's premises or due to a cashier's error when the customer is checking out). The outcome of these errors is a discrepancy among inventory levels as they appear in the organization's inventory systems and the actual inventory available for sale. These discrepancies can be prevented in situations in which additional information about them is available to decision makers. The study included four different models that related to four different cases of these errors: the case in which no one is aware of these errors, the case in which the organization is aware of the chance that these errors will occur and sets a policy of maintaining a fixed level of inventory, the case in which the organization is aware of the chance that the standard deviation of these errors will occur and so sets a policy of a dynamic inventory level and the case in which a data system provides information about all errors in practice. The objective of the research was to find the value of additional information in each of the three cases when compared to the basic case when the organization is unaware of the existence of any errors. An analytical model was developed for each case. The study's findings showed that the additional information has a significant impact on the optimal management policy, as well as found that there are parameters that affect the value of the additional information less and other parameters that impact the value of the information significantly more. In addition, Avrahami investigated and quantified the value of additional information in the distribution system that is based on a retail chain serving a central company. He studied the value of the ability to review the situation in the system much more frequently than is usually done.

[4] Presented a case study from the paper reel industry. They developed a simulation model in order to study the value of deploying an RFID system in a printing house. As can be seen, the latter study focused on simulation and an empirical analysis. It was a small study whose objective was to develop analytical models that only covered some sources of errors. Accordingly, they chose to implement a broader analytical model that covered more error sources and facilitated the estimations of savings in different cases in different scenarios. The main conclusions when looking at the history were that errors should not be neglected and that systems that take into consideration these errors demonstrate a higher performance level. They used these conclusions to study the error sources and determine how to model them in order to assist decision makers in deciding when it is practical to invest in additional information.

[3] Described cooperation between a distribution organization within the Yedioth Group, the largest media company in Israel, the Technion-Israel Institute of Technology in Haifa, and the Massachusetts Institute of Technology in the U.S. This collaboration led to basic changes in the way Yedioth distributes printed magazines and newspapers. In this study the researchers developed and implemented decision making support tools, based on new models and algorithms, which are operated through an electronic data interchange (EDI) program, and in the future will be operated through an RFID technological solution system. The rationale behind this is the use of information about sales in the stores in real-time in order to allow inventory pooling in the chain. The researchers leverage the data for use in an additional implementation of a new distribution period in the course of a week, and delay the distribution of some magazines until partial sales data is received. The authors modeled the systems as a stochastic optimization model with two stages. Furthermore, they showed that the cost obtained is convex for the decision variables. This approach was formulated by a multi-dimensional dynamic program. By formulating the second stage, the secondary issue of a linear program, they developed a stochastic tool based on an algorithm for innovative optimization that found that the optimal solution is calculated in seconds. The changes arising from the collaboration led to significant savings in costs in Yedioth in terms of reduction in production levels of magazines and in the levels of returns. These savings were achieved while maintaining the same level of sales.

[5] Presented the fact that information has value in the management of supply chains is well accepted. The paper focuses on the value of the quality of information. In particular the authors are concerned with discrepancies known as inventory errors, which are the result of one of three events: shrinkage, misplacement and wrong-scanning. The outcome of these events is discrepancies between IT inventory (inventory as it appears in the computerized system) and available inventory for sale. They explore four information scenarios that operationally take these errors into consideration. The objective of their work is to explore and quantify the value of more accurate information. To this end, they formulate and solve an analytical model for each scenario whose objective is to minimize the expected average cost per period. Their computational study shows that more accurate information can be exploited to significantly reduce costs.

[7] Presents a two stage model with front shelf and back room. Each of the stages is prone to three types of errors. The base model is continuous $(Q, R)$ inventory system. The authors present empirical study with Bayesian computations based on data from global retail chain. Finally, a connection between part time/full time labor and inventory record inaccuracy is shown. 
[17] Analyze a periodic inventory auditing in order to deal with stock inaccuracy. They provide a recursive solution to single stage problem, show more effective methods of cycle count in two stage problem and explain why cycle counting is needed in all stages, not only the ones with high priority.

[25] Displays the Technology of RFID. The paper focus on single item, single period, centralized and decentralized supply chains. Two inventory errors are modeled-shrinkage and misplacement while the demand is uniform. The authors show the relationships between RFID costs, optimal order quantities and profits.

\section{Description of the Problem}

The development of new technologies for acquiring information (RFID - is a data capture technology, EDI - is a data sharing technology) has over time changed the mutual relations between the value of information and the cost of acquiring this information. The literature shows that gaps in information between different types of inventory in different industries were identified. The added value brought by the present paper is in identifying the gaps in the print industry itself and the operationalizing of analytical models for coping with these gaps. Accordingly, there is a simple, yet general, need for a tool that can support management decisions in the print industry-identification of inventory gaps in the print industry and implementation of a model to handle the gap with the objective of finding potential savings.

Of course we can identify the gaps between IT inventory entries and Available inventory for sale in all industries, because this information scenarios appropriate to the current reality in warehouses in every industry. We chose to test these scenarios and gaps at printing industry we work today because of the availability and accessibility of data for us.

After identifying the gaps between the IT system's inventory and the physical inventory of auxiliary and raw materials, we calculated the ranges of the discrepancies between the types of inventory. For each item, we quantified from the total gap we found between the IT and physical inventories, the range of shrinkage, wrong scanning and misplacement errors. In [2] the range of errors of the total consumption per item is $1 \%, 0.008 \%$ and $0.008 \%$ for shrinkage, wrong scanning and misplacement, respectively. In our work we normalized the range of errors from the total consumption, as can be seen in Table 1, as this appears in the literature for the range of errors of the absolute total gap that we found in our work for each item $98.43 \%, 0.78 \%, 0.79 \%$ for shrinkage, wrong scanning and misplacement, respectively.

Table 1: Normalization of the range of errors of the total consumption

\begin{tabular}{|l|l|l|l|}
\cline { 2 - 4 } \multicolumn{1}{c|}{} & $\begin{array}{l}\text { Relation of } \\
\text { Sources to } \\
\text { demand } \\
\text { (Avrahami, } \\
2012)\end{array}$ & $\begin{array}{l}\text { Normalization to } \\
\text { total number of } \\
\text { errors that were } \\
\text { actually found }\end{array}$ & Calculation \\
\hline Shrinkage error & 1 & 98.43 & $\left(100^{\star} 1\right) / 1.016=98.43$ \\
\hline Misplacement error & 0.008 & 0.79 & $\left(100^{\star} 0.008\right) / 1.016=0.79$ \\
\hline Wrong scanning error & 0.008 & 0.79 & $\left(100^{\star} 0.008\right) / 1.016=0.79$ \\
\hline sum & 1.016 & 100 & \\
\hline
\end{tabular}

We propose to respond to the inaccuracies presented above using four different scenarios corresponding to the costs described in [2].

\section{Approaches to Solution}

One can respond to discrepancies between the inventory appearing in the IT system and the inventory available for sale using four different scenarios, as reviewed above:

1. No Information Scenario - In the No Information Scenario, the inventory manager is not aware that errors occur and he or she orders stock according to the regular periodic inventory review. In the No Information Scenario the expected cost changes as time passes, as a result of errors that accumulate from one period to the next.

2. Informed Scenario - In this scenario the manager making decisions is aware that errors are occurring and knows the distribution (expected value and standard deviation) of these errors. The optimal policy in a 
system that contains errors (which, undoubtedly, is the case in most inventory systems) is static. Despite the optimal policy being a base stock one, the base inventory level changes over time as a result of the random variable of demand and the components of relevant errors.

3. Static Informed Scenario - This is identical to the Informed Scenario except that here the inventory manager uses only information about the expected value of errors and not their distribution. He does this as part of the need to implement a static base stock policy (which is, clearly, easier to implement) and in light of the fact that this is the only information available. The development is almost identical that in the Informed Scenario. When replenishing inventory, the inventory manager uses the expected value of errors when calculating the basic stock level. Accordingly, the random variable is the same as in the Informed Scenario, only here the expected value of the variables of random errors is used and not the errors themselves.

The two Informed Scenarios, the Static Informed Scenario-which can be viewed as a static version of the Informed Scenario-and the No Information Scenario-which ignores one of the errors-use a static base stock policy.

4. The Full Information Scenario-With complete information, misplacement errors are revealed immediately and wrong scanning errors do not happen. We assume that shrinkage still occurs, even though some researchers in the area of modern information data collection systems claim that they have reduced shrinkage. Nevertheless, shrinkage occurs but is immediately known.

Each scenario presented above incurs different costs. All the cost calculations are based on variations of the newsvendor model. Each scenario requires a different quantity of information. The key to the research is the value of this information, which delineates the cost difference between the scenario with less data and the scenario with more data.

Each scenario comprises a possible methodology for solving the problem. The aim is to determine which scenario offers the greatest economic benefit. To this end, we built a simulation and used the data collected in the printing house to run it.

We use the News Vendor model (Lau, 1996) to model our problem because this model has the ability to take into consideration the random demand and the approach to solve optimal solution. This model is common in the print industry.

\subsection{Solution Stages}

1. Selecting the type of items among which we want to identify the gap between the IT inventory and the physical inventory. The objective is to match the volume of work to the time that was determined for it. We chose to focus on the main auxiliary and raw materials in which gaps were found in the last four years.

2. Data gathering-we identified the gaps in the auxiliary and raw materials between what was reported to the IT system and what was physically counted during the inventory in 2010, 2011, 2012 and 2013. The gaps were presented as absolute numbers and as a percentage of the total consumption of the respective item. Likewise, the consumption cost and the cost of each item were presented.

3. We calculated the average and the standard deviation for the consumption quantity of each item.

4. As we described in the above paragraph, from the total gap that we found between the IT inventory and the physical inventory, we quantified for each item the range of shrinkage, wrong scanning and misplacement errors.

5. For each item, we calculated the cost of not having the item (p), and the cost of having it in inventory (h). The cost of the missing item is represented by $p$ and constitutes the damage that will be caused to the organization because of the absence of a certain item in the inventory when it is needed. The greater the cost of the missing item, the larger will be the quantity of this item kept in the inventory and vice versa. Using economic estimations, we determined that the cost of maintaining the inventory is $10 \%$ of the cost of the item and the cost of not having the item was determined such that the critical relationship $(p /(p+h))$ for this item is high and must be equal to 0.9 in order to represent a realistic demand for the system. The reason for setting a high critical relationship is rooted in the fact that the press industry is critical and that lack of an item may cause greater damage than having too much of the same item.

See Table 2 that Summarize the data used in the print auxiliary material simulation. 
Table 2: Summary of the data used in the print auxiliary material simulation

\begin{tabular}{|c|c|c|c|c|c|c|c|c|c|c|}
\hline Item & $\begin{array}{l}\text { mu_d, } \\
\text { average } \\
\text { consum } \\
\text { ption }\end{array}$ & $\begin{array}{l}\text { sig_d, } \\
\text { standard } \\
\text { deviation } \\
\text { of } \\
\text { consumpti } \\
\text { on }\end{array}$ & $\begin{array}{l}\text { mu_s, } \\
\text { average } \\
\text { shrinkag } \\
\text { e error }\end{array}$ & $\begin{array}{l}\text { sig_s, } \\
\text { shrinka } \\
\text { ge error } \\
\text { standar } \\
\text { d } \\
\text { deviatio } \\
\text { n }\end{array}$ & $\begin{array}{l}\text { mu_m, } \\
\text { averag } \\
\text { e } \\
\text { mispla } \\
\text { cemen } \\
\text { t error }\end{array}$ & $\begin{array}{l}\text { sig_m, } \\
\text { misplace } \\
\text { ment } \\
\text { error } \\
\text { standard } \\
\text { deviation }\end{array}$ & $\begin{array}{l}\text { mu_w, } \\
\text { average } \\
\text { wrong } \\
\text { scannin } \\
\text { g error }\end{array}$ & $\begin{array}{l}\text { sig_w, } \\
\text { wrong } \\
\text { scanni } \\
\text { ng } \\
\text { standa } \\
\text { rd } \\
\text { deviati } \\
\text { on }\end{array}$ & $\begin{array}{l}\mathrm{h}, \\
\text { cost of } \\
\text { having } \\
\text { a } \\
\text { surplus } \\
\text { of the } \\
\text { time for } \\
\text { a year }\end{array}$ & $\begin{array}{l}P, \\
\text { cost of } \\
\text { missing } \\
\text { item for } \\
\text { a year }\end{array}$ \\
\hline $\begin{array}{l}\text { Two-sided green tape } 50 \\
\mathrm{~mm} / 33 \mathrm{~m} 9411\end{array}$ & 1,040 & 86.76 & 0.49 & 0.98 & 0.00 & 0.01 & 0.00 & 0.01 & 3.78 & 34.04 \\
\hline Brown PVC tape & 332 & 30.64 & 0.74 & 0.94 & 0.01 & 0.01 & 0.01 & 0.01 & 0.48 & 4.31 \\
\hline $\begin{array}{l}\text { Antistatic spray - dust } \\
\text { repellent }\end{array}$ & 172 & 27.79 & 1.48 & 1.88 & 0.01 & 0.02 & 0.01 & 0.02 & 1.61 & 14.50 \\
\hline $\begin{array}{l}73-85 \text { plastic bags, red } \\
\text { with Yedioth Aharonot } \\
\text { printed on the side, } 250 \\
\text { units per carton }\end{array}$ & 344 & 62.79 & 13.04 & 24.15 & 0.10 & 0.19 & 0.10 & 0.19 & 18.51 & 166.55 \\
\hline $\begin{array}{l}\text { Twine for distribution core } \\
200 \mathrm{~mm}\end{array}$ & 1,329 & 21.32 & 0.98 & 1.97 & 0.01 & 0.02 & 0.01 & 0.02 & 12.77 & 114.95 \\
\hline Nitrile disposable gloves & 760 & 88.35 & 0.74 & 1.48 & 0.01 & 0.01 & 0.01 & 0.01 & 1.78 & 16.04 \\
\hline Cream masking tape & 221 & 48.34 & 1.23 & 1.48 & 0.01 & 0.01 & 0.01 & 0.01 & 0.62 & 5.56 \\
\hline $\begin{array}{l}\text { Corner reinforcement - } \\
\text { rigid carton } 9^{*} 9\end{array}$ & 3,203 & 2559.69 & 108.27 & 216.54 & 0.87 & 1.73 & 0.87 & 1.73 & 0.24 & 2.18 \\
\hline Pink top sheet paper & 200 & 59.51 & 1.48 & 2.34 & 0.01 & 0.02 & 0.01 & 0.02 & 10.99 & 98.92 \\
\hline $\begin{array}{l}\text { Cotton rag, with no } \\
\text { buttons, zippers etc. }\end{array}$ & 7,563 & 253.29 & 61.52 & 116.56 & 0.49 & 0.93 & 0.49 & 0.93 & 0.25 & 2.29 \\
\hline Spray - safe fats dissolver & 211 & 44.95 & 0.25 & 0.49 & 0.00 & 0.00 & 0.00 & 0.00 & 1.13 & 10.19 \\
\hline $\begin{array}{l}\text { Pink A4 paper } 80 \text { gram } \\
\text { for a Yazamko printer }\end{array}$ & 416 & 73.76 & 2.21 & 3.80 & 0.02 & 0.03 & 0.02 & 0.03 & 7.63 & 68.63 \\
\hline $\begin{array}{l}\text { BD100 cylinder cleaning } \\
\text { material }\end{array}$ & 347 & 209.84 & 0.25 & 0.49 & 0.00 & 0.00 & 0.00 & 0.00 & 1.59 & 14.31 \\
\hline Ribbon for tying $9 \mathrm{~mm}$ & 272 & 9.11 & 1.23 & 2.46 & 0.01 & 0.02 & 0.01 & 0.02 & 13.52 & 121.70 \\
\hline Wooden pallet $100 * 120$ & 13,837 & 629.61 & 189.47 & 378.94 & 1.52 & 3.03 & 1.52 & 3.03 & 1.70 & 15.27 \\
\hline $\begin{array}{l}\text { Stretchable nylon for } \\
\text { wrapping wagons } \\
\text { manually }\end{array}$ & 3,621 & 1368.29 & 16.24 & 32.48 & 0.13 & 0.26 & 0.13 & 0.26 & 1.82 & 16.38 \\
\hline $\begin{array}{l}\text { Disinfected wooden pallet } \\
70^{*} 100\end{array}$ & 3,886 & 5850.02 & 11.56 & 23.13 & 0.09 & 0.19 & 0.09 & 0.19 & 1.63 & 14.68 \\
\hline \multicolumn{11}{|l|}{ Table 2: Continuation } \\
\hline $\begin{array}{l}\text { Machine stretchable nylon } \\
360 \%\end{array}$ & 351 & 22.25 & 0.98 & 1.97 & 0.01 & 0.02 & 0.01 & 0.02 & 16.72 & 150.46 \\
\hline Twine \# 700 & 185 & 41.72 & 0.74 & 1.48 & 0.01 & 0.01 & 0.01 & 0.01 & 3.20 & 28.80 \\
\hline $\begin{array}{l}\text { Twine for distribution core } \\
200\end{array}$ & 1,329 & 21.32 & 6.40 & 12.80 & 0.05 & 0.10 & 0.05 & 0.10 & 12.77 & 114.95 \\
\hline Brown crepe paper & 1,047 & 104.69 & 17.72 & 35.43 & 0.14 & 0.28 & 0.14 & 0.28 & 10.05 & 90.45 \\
\hline $\begin{array}{l}\text { Yellow A4 paper } 80 \text { gram } \\
\text { for a Yazamko printer }\end{array}$ & 133 & 20.04 & 1.97 & 3.94 & 0.02 & 0.03 & 0.02 & 0.03 & 7.57 & 68.11 \\
\hline $\begin{array}{l}\text { White A4 paper } 80 \text { gram } \\
\text { for a Yazamko printer }\end{array}$ & 650 & 185.66 & 4.92 & 9.84 & 0.04 & 0.08 & 0.04 & 0.08 & 5.92 & 53.25 \\
\hline $\begin{array}{l}\text { Green A4 paper } 80 \text { gram } \\
\text { for a Yazamko printer }\end{array}$ & 134 & 16.22 & 0.98 & 1.97 & 0.01 & 0.02 & 0.01 & 0.02 & 7.56 & 68.01 \\
\hline Tricot XL gloves & 10,599 & 952.22 & 63.73 & 127.46 & 0.51 & 1.02 & 0.51 & 1.02 & 0.13 & 1.18 \\
\hline $\begin{array}{l}\text { Prownews R-52-S water } \\
\text { additive }\end{array}$ & 28,631 & 4024.17 & 1119.59 & 2239.17 & 8.96 & 17.91 & 8.96 & 17.91 & 0.62 & 5.55 \\
\hline Plates & 637,113 & 38421.36 & 12152.56 & 5781.40 & 97.22 & 46.25 & 97.22 & 46.25 & 0.70 & 6.28 \\
\hline
\end{tabular}

\subsection{List of Symbols for the Electronic Spreadsheet}

- mu_s - average shrinkage error

- $\quad$ sig_s - shrinkage error standard deviation

- $\quad$ mu_m - average misplacement error

- $\quad$ sig_m - misplacement error standard deviation

- $\quad$ mu_w - average wrong scanning error

- $\quad$ sig_w - wrong scanning standard deviation

- $\quad p$ - cost of missing item for a year

- $\quad \mathrm{h}$ - cost of having a surplus of the time for a year (cost of holding it in inventory) 
- $\quad$ pic_f - additional periodic cost of information

- mu_d_tilda - average consumption with the addition of average error sources

- $\quad$ sig_d_tilda - standard deviation of consumption with the addition of the standard deviation from error sources

- $\quad$ mu_ds - average consumption with the addition of average shrinkage error

- $\quad$ sig_ds - standard deviation of consumption with the addition of shrinkage error standard deviation

- $\quad F-1$ (crit Ratio) - the inverse value of the critical value $(p /(p+h))$

- $\mathrm{Q}$ - quantity to be purchased in accordance to the respective scenario

- $\quad E C N(Q)$ - expected value of the anticipated cost for the quantity to be purchased $Q$

See Table 3 that summarize the data that was collected during the solution process.

Table 3: Summary of the data used in the print raw material simulation

\begin{tabular}{|l|l|l|l|l|l|l|l|l|l|l|}
\cline { 2 - 8 } \multicolumn{1}{c|}{} & $\begin{array}{l}\text { mu_d, } \\
\text { average } \\
\text { consumpt } \\
\text { ion }\end{array}$ & $\begin{array}{l}\text { sig_d, } \\
\text { standard } \\
\text { deviation } \\
\text { of } \\
\text { consumpt } \\
\text { ion }\end{array}$ & $\begin{array}{l}\text { mu_s, } \\
\text { average } \\
\text { shrinkage } \\
\text { error }\end{array}$ & $\begin{array}{l}\text { sig_s, } \\
\text { shrinkage } \\
\text { error } \\
\text { standard } \\
\text { deviation }\end{array}$ & $\begin{array}{l}\text { mu_m, } \\
\text { average } \\
\text { misplace } \\
\text { ment } \\
\text { error }\end{array}$ & $\begin{array}{l}\text { sig_m, } \\
\text { misplace } \\
\text { ment } \\
\text { error } \\
\text { standard } \\
\text { deviation }\end{array}$ & $\begin{array}{l}\text { mu_w, } \\
\text { average } \\
\text { wrong } \\
\text { scanning } \\
\text { error }\end{array}$ & $\begin{array}{l}\text { sig_w, } \\
\text { wrong } \\
\text { scanning } \\
\text { standard } \\
\text { deviation }\end{array}$ & $\begin{array}{l}\text { h, } \\
\text { cost of } \\
\text { having a } \\
\text { surplus of } \\
\text { the time } \\
\text { for a year }\end{array}$ \\
\hline Yellow ink & 126,250 & 8,421 & 0 & 0 & 0 & 0 & $\begin{array}{l}\text { P, } \\
\text { cost of } \\
\text { missing } \\
\text { item for a } \\
\text { year }\end{array}$ \\
\hline Red ink & 90,750 & 11,673 & 0 & 0 & 0 & 0 & 0 & 0 & 1.32 \\
\hline Blue ink & 99,875 & 4,661 & 0 & 0 & 0 & 0 & 0 & 11.84 \\
\hline Black ink & 145,225 & 15,468 & 0 & 0 & 0 & 0 & 0 & 0 & 0 \\
\hline $\begin{array}{l}\text { Paper } \\
\text { reels }\end{array}$ & 18,504 & 810 & 8.12 & 3.80 & 0.06 & 0.03 & 0.06 & 0.03 & 1.31 \\
\hline
\end{tabular}

After collecting and processing the data, we implemented a newsvendor model through an Excel@ simulation, with the addition of the error sources and in the context of the four scenarios. As a first step, after collecting the data, we built a simulation model on an electronic spreadsheet based on the newsvendor model with the addition of the discrepancies between the IT inventory and the available-for-sale inventory relating to the three error sources for each information scenario. The model was based on the annual average and standard deviation of item consumption and the annual average and standard deviation of the error sources. We constructed a precise ordering forecast, presented our conclusions and recommendations according to the scenario that was worthwhile following in terms of economics in each case.

The following is the model that was implemented:

\section{Notation:}

- $\mathrm{Q}$ - quantity to be purchased

- $\mathrm{Q}^{*}$ - optimal quantity to be purchased

- $\quad E C N(Q)$ - anticipated cost of the purchased quantity $Q$

- $\quad E C N\left(Q^{*}\right)$ - anticipated cost of the purchased quantity $Q^{*}$

- $\mu$ - annual average consumption of the item

- $\sigma$ - annual average consumption of the item

- $\rho$ - annual cost of not having the item in stock

- $\quad \mathrm{h}$ - annual cost of having a surplus of the item in stock (cost of holding it inventory)

- $\quad$ Z - random variable that is distributed normally

- $\phi(Z)$ - cumulative normal distribution function 


\section{- $\emptyset(Z)$ - anticipated normal distribution function}

The anticipated cost for one period is the cost of our decision of how much to purchase and can be calculated using the following equations [16]:

Anticipated cost for purchase of quantity $Q$ :

$$
E C N(Q)=\sigma\{-p Z+(h+p)[Z \phi(Z)+\phi(Z)]\}
$$

When

$$
Z=(Q-\mu) / \sigma
$$

Anticipated cost for purchase of quantity $Q^{*}$ :

$$
\operatorname{ECN}\left(Q^{*}\right)=\sigma(h+p)^{*} \phi(Z)
$$

We use the above equations for each Informed Scenario. Accordingly, $Q, \mu$ and $\sigma$ change from scenario to scenario. For the No Information Scenario we used the well-known simple newsvendor model to calculate the quantity to order, which was based on the distribution of demand. In this scenario the inventory manager is unaware of errors yet in reality they still occur, and as a result, the quantity that he orders is not optimal and produces a different cost than the one he calculated. In line with this, we chose to relate to two costs: expected value of the anticipated cost that the inventory manager calculated and the expected value of the anticipated cost that the inventory manager will actually incur. These costs are presented into two columns under the respective scenario. The right column shows the expected value of the cost calculated by the inventory manager as the cost of the decision to purchase quantity $\mathrm{Q}$ (theoretical EC), relating to the demand distribution only. However, in fact, the reality is different and the errors we discussed above occur. The left column in the scenario presents the actual expected value of the anticipated cost (Actual EC) to the inventory manager, relating to the distribution of errors in addition to the demand distribution. Of course, the expected value of the actual anticipated cost is high compared to the expected value of the theoretical anticipated cost, given that this relates to the distribution of errors and the cost of holding surplus inventory that is paid as a result of misplacement errors.

For the Informed Scenario, we used the well-known newsvendor model, relating to the distribution of demand and errors in order to calculate the quantity to order and the expected value of the anticipated cost, given that in this scenario the inventory manager is aware that errors occur and knows their distribution.

For the Static Informed Scenario, we used the well-known newsvendor model, relating to the distribution of demand and the expected value of the errors only, given that in this scenario the inventory manager is aware of the expected value of the errors that occur but not their distribution. In order to calculate the expected value of the anticipated cost, we related to the demand and error distributions because, in reality, errors occur and their distribution occurs.

For the Full Information Scenario, we used the well-known newsvendor model to calculate the quantity ordered and the expected value of the anticipated cost, relating to the demand and shrinkage error distribution only, given that in this scenario the inventory manager is aware of all the errors and handles them all except for the shrinkage, which cannot be completely avoided and still occurs. In this scenario, an additional component is added to the expected value of the anticipated cost. This component represents the additional periodic cost of information (Pic_F). The cost $\mathrm{F}$ for a system that provides complete information is based on the cost of the RFID technology whose implementation was previously tested in the printing house. This cost includes the cost of initial investment (data reading gates and software) and the ongoing costs (tags). This data is relevant for a number of industries (print, retailing, communication and more).

It is important to note that the expected value of the anticipated cost in the three scenarios-No Information, Informed and Static Informed-was calculated using the non-optimal quantity purchasing cost equation, whereas the expected value of the anticipated cost for the Full Information Scenario was calculated using the cost of purchasing an optimal quantity since in this scenario the inventory manager reacts to all errors in order to prevent them and orders the optimal quantity. For the scenario in which misplacement errors occur, the respective cost of holding inventory was taken into consideration. For each inventory review as well as for each scenario, we calculate the anticipated cost using input.

\section{Results}

The objective of this section is to investigate the behavior of our findings in numerical terms for the values of different parameters and to get insight about the behavior of our model. We will calculate the average anticipated cost of the different informed scenarios for each data set. We limit our study to random variables with normal distribution. 
Based on the data we collected in the printing house, we conducted a simulation on an electronic spreadsheet. Table 4 and 5 present the results.

Table 4: Validity and reliability of the auxiliary print material model

\begin{tabular}{|c|c|c|c|c|c|c|c|c|c|}
\hline \multicolumn{5}{|l|}{ 『 EC_N(Q) } & \multicolumn{4}{|l|}{ Q } & \\
\hline $\begin{array}{c}\text { Simple } \\
\text { NV - No } \\
\text { informatio } \\
\mathrm{n} \text { (actual) }\end{array}$ & $\begin{array}{l}\text { Simple NV - } \\
\text { No } \\
\text { information } \\
\text { (theoretical) }\end{array}$ & $\begin{array}{l}\text { Full } \\
\text { information }\end{array}$ & Informed & $\begin{array}{l}\text { Static } \\
\text { informed }\end{array}$ & $\begin{array}{l}\text { Simple } \\
\text { NV - No } \\
\text { information }\end{array}$ & $\begin{array}{l}\text { Full } \\
\text { information }\end{array}$ & Informed & $\begin{array}{l}\text { Static } \\
\text { informed }\end{array}$ & \\
\hline 575.6951 & 575.6338 & 580.6705 & 575.6853 & 575.6853 & $1,151.2136$ & $1,151.7107$ & $1,151.7185$ & $1,151.7114$ & $\begin{array}{l}\text { Two-sided } \\
\text { green tape } \\
50 \mathrm{~mm} / 33 \\
\mathrm{~m} 9411\end{array}$ \\
\hline 25.8217 & 25.7964 & 30.8085 & 25.8133 & 25.8133 & 371.2303 & 371.9888 & 372.0088 & 371.9903 & $\begin{array}{l}\text { Brown PVC } \\
\text { tape }\end{array}$ \\
\hline 78.8601 & 78.5344 & 83.7139 & 78.7301 & 78.7301 & 207.6241 & 209.1856 & 209.2056 & 209.1241 & $\begin{array}{l}\text { Antistatic } \\
\text { spray - dust } \\
\text { repellent }\end{array}$ \\
\hline $2,284.9540$ & $2,039.5980$ & $2,190.2548$ & $2,187.1232$ & $2,187.1232$ & 424.4609 & 443.2470 & 443.4477 & 437.7009 & $\begin{array}{l}73-85 \\
\text { plastic } \\
\text { bags, red } \\
\text { with } \\
\text { Yedioth } \\
\text { Aharonot } \\
\text { printed on } \\
\text { the side, } \\
250 \text { units } \\
\text { per carton }\end{array}$ \\
\hline 480.6562 & 477.8256 & 484.8611 & 479.9893 & 479.9893 & 1,356.3246 & $1,357.4210$ & $1,357.4410$ & 1,357.3246 & $\begin{array}{l}\text { Twine for } \\
\text { distribution } \\
\text { core } 200 \\
\mathrm{~mm} \\
\end{array}$ \\
\hline 276.1448 & 276.0775 & 281.1163 & 276.1341 & 276.1341 & 873.2816 & 874.0375 & 874.0575 & 874.0416 & $\begin{array}{l}\text { Nitrile } \\
\text { disposable } \\
\text { gloves }\end{array}$ \\
\hline 52.6018 & 52.5524 & 57.5770 & 52.5832 & 52.5832 & 282.8612 & 284.1202 & 284.1402 & 284.1112 & $\begin{array}{l}\text { Cream } \\
\text { masking } \\
\text { tape }\end{array}$ \\
\hline $1,085.8549$ & $1,080.5428$ & $1,089.4023$ & $1,084.6116$ & $1,084.6116$ & $6,495.4652$ & $6,615.4955$ & $6,617.2370$ & $6,605.4752$ & $\begin{array}{l}\text { Corner } \\
\text { reinforceme } \\
\text { nt - rigid } \\
\text { carton } 9 * 9\end{array}$ \\
\hline $1,149.2083$ & $1,147.8134$ & $1,153.7004$ & $1,148.8103$ & $1,148.8103$ & 276.2682 & 277.8072 & 277.8272 & 277.7682 & $\begin{array}{l}\text { Pink top } \\
\text { sheet paper }\end{array}$ \\
\hline 131.2764 & 111.6050 & 127.8553 & 122.9791 & 122.9791 & 7,889.8902 & $7,984.3621$ & 7,985.3461 & 7,952.3902 & $\begin{array}{l}\text { Cotton rag, } \\
\text { with no } \\
\text { buttons, } \\
\text { zippers etc. }\end{array}$ \\
\hline 89.1910 & 89.1843 & 94.1896 & 89.1896 & 89.1896 & 268.6510 & 268.9044 & 268.9044 & 268.9010 & $\begin{array}{l}\text { Spray - safe } \\
\text { fats } \\
\text { dissolver }\end{array}$ \\
\hline 989.5261 & 987.5452 & 993.8549 & 989.0077 & 989.0077 & 510.5052 & 512.8405 & 512.8806 & 512.7552 & $\begin{array}{l}\text { Pink A4 } \\
\text { paper } 80 \\
\text { gram for a } \\
\text { Yazamko } \\
\text { printer }\end{array}$ \\
\hline 585.5477 & 585.5425 & 590.5441 & 585.5472 & 585.5472 & 615.9208 & 616.1715 & 616.1755 & 616.1748 & $\begin{array}{l}\text { BD100 } \\
\text { cylinder } \\
\text { cleaning } \\
\text { material }\end{array}$ \\
\hline 227.8123 & 216.1650 & 228.9075 & 224.0437 & 224.0437 & 283.6757 & 285.3239 & 285.3440 & 284.9257 & $\begin{array}{l}\text { Ribbon for } \\
\text { tying } 9 \mathrm{~mm}\end{array}$ \\
\hline $2,454.2886$ & $1,877.5284$ & $2,196.3588$ & $2,193.9801$ & $2,193.9801$ & $14,643.2439$ & $14,967.4782$ & $14,970.5342$ & $14,835.7539$ & $\begin{array}{l}\text { Wooden } \\
\text { pallet } \\
100 * 120 \\
\end{array}$ \\
\hline $4,372.2202$ & $4,370.4135$ & $4,376.6447$ & $4,371.8814$ & $4,371.8814$ & $5,374.5342$ & $5,391.2682$ & $5,391.5282$ & $5,391.0342$ & $\begin{array}{l}\text { Stretchable } \\
\text { nylon for } \\
\text { wrapping } \\
\text { wagons } \\
\text { manually } \\
\end{array}$ \\
\hline $16,737.7808$ & $16,737.4692$ & $16,742.6000$ & $16,737.746$ & $16,737.746$ & $11,385.1465$ & $11,396.7651$ & $11,396.9451$ & $11,396.8865$ & $\begin{array}{l}\text { Disinfected } \\
\text { wooden } \\
\text { pallet } \\
70^{*} 100 \\
\end{array}$ \\
\hline 656.4184 & 652.8678 & 660.4218 & 655.5895 & 655.5895 & 379.5130 & 380.6045 & 380.6246 & 380.5130 & $\begin{array}{l}\text { Machine } \\
\text { stretchable } \\
\text { nylon } 360 \% \\
\end{array}$ \\
\hline 234.5194 & 234.2973 & 239.4447 & 234.4767 & 234.4767 & 238.4663 & 239.2400 & 239.2600 & 239.2263 & $\begin{array}{l}\text { Twine \# } \\
700\end{array}$ \\
\hline
\end{tabular}




\begin{tabular}{|c|c|c|c|c|c|c|c|c|c|}
\hline 623.8209 & 477.8256 & 562.3279 & 557.9754 & 557.9754 & $1,356.3246$ & $1,367.2709$ & $1,367.3715$ & $1,362.8246$ & $\begin{array}{l}\text { Twine for } \\
\text { distribution } \\
\text { core } 200\end{array}$ \\
\hline $2,007.7864$ & $1,846.4785$ & $1,954.3543$ & $1,950.7738$ & $1,950.7738$ & $1,181.1656$ & $1,206.3606$ & $1,206.6415$ & $1,199.1656$ & $\begin{array}{l}\text { Brown } \\
\text { crepe paper }\end{array}$ \\
\hline 273.6086 & 266.2169 & 276.3133 & 271.4653 & 271.4653 & 158.6793 & 161.1409 & 161.1809 & 160.6893 & $\begin{array}{l}\text { Yellow A4 } \\
\text { paper } 80 \\
\text { gram for a } \\
\text { printer }\end{array}$ \\
\hline 1,932.3997 & $1,928.6510$ & $1,936.3579$ & $1,931.5951$ & $1,931.5951$ & 887.8792 & 893.1331 & 893.2131 & 892.8792 & $\begin{array}{l}\text { White A4 } \\
\text { paper } 80 \\
\text { gram for a } \\
\text { Yazamko } \\
\text { printer }\end{array}$ \\
\hline 217.3917 & 215.1786 & 221.7599 & 216.8358 & 216.8358 & 154.7831 & 155.9158 & 155.9359 & 155.7831 & $\begin{array}{l}\text { Green A4 } \\
\text { paper } 80 \\
\text { gram for a } \\
\text { Yazamko } \\
\text { printer }\end{array}$ \\
\hline 220.4084 & 217.6957 & 224.6373 & 219.7038 & 219.7038 & $11,823.4725$ & $11,898.1234$ & $11,899.1448$ & $11,888.2225$ & $\begin{array}{l}\text { Tricot XL } \\
\text { gloves }\end{array}$ \\
\hline $5,502.5581$ & $4,372.9255$ & $5,009.3058$ & $5,009.9367$ & $5,009.9367$ & $33,777.0520$ & $35,639.6494$ & $35,657.6584$ & $34,914.5620$ & $\begin{array}{l}\text { Prownews } \\
\text { R-52-S } \\
\text { water } \\
\text { additive }\end{array}$ \\
\hline $50,776.5472$ & $47,163.7497$ & $47,699.708$ & $47,762.830$ & $47,762.830$ & $686,289.289$ & $698,995.4657$ & $699,189.9761$ & $698,636.2897$ & Plates \\
\hline
\end{tabular}

Table 5: Validity and reliability of the print raw material model

\begin{tabular}{|c|c|c|c|c|c|c|c|c|c|}
\hline \multicolumn{5}{|c|}{ ๗ EC_N(Q) } & \multicolumn{4}{|c|}{ Q } & \\
\hline $\begin{array}{l}\text { Simple NV - } \\
\text { No information } \\
\text { (actual) }\end{array}$ & $\begin{array}{l}\text { Simple NV - } \\
\text { No information } \\
\text { (theoretical) }\end{array}$ & Full & Informed & $\begin{array}{l}\text { Static } \\
\text { informed }\end{array}$ & $\begin{array}{l}\text { Simple } \\
\text { NV - No } \\
\text { information }\end{array}$ & \begin{tabular}{|l} 
Full \\
information
\end{tabular} & Informed & $\begin{array}{l}\text { Static } \\
\text { informed }\end{array}$ & \\
\hline $244,457.4104$ & $244,431.6653$ & $244,439.3551$ & $244,444.6724$ & $244,444.6724$ & $19,542.0460$ & $19,550.1775$ & $19,550.2975$ & $19,550.2860$ & $\begin{array}{l}\text { Paper } \\
\text { reels }\end{array}$ \\
\hline
\end{tabular}

Tables 4 and 5 present the simulation results that we received for the items (print auxiliary and raw materials). The four sub-columns under the $Q$ header present the quantities to order for each scenario that we reviewed in our work. The succeeding five sub-columns under the EC_N(Q) present the expected value of the anticipated cost for each scenario when purchasing quantity $Q$. This cost is the cost of our decision reached following the decision regarding the quantity to purchase $\mathrm{Q}$. The scenario and the optimal inventory policy that the inventory manager should follow is determined in accordance with this cost.

Under the No Information Scenario, there are two columns that present the expected value of the anticipated cost for purchasing quantity $\mathrm{Q}$. The right column under this scenario presents the cost that the inventory manager calculated whereas the left column, in the same scenario, shows the actual costs that the inventory manager will have to pay for purchasing quantity $\mathrm{Q}$.

Intuitively, we can sense that when demand grows, the costs change and increase. Intuitively, this is based on change in the uncertainty that is represented by the parameter sig $\mathrm{d}$. Parameter $\mathrm{F}$, which represents the periodic cost of additional information, has a large but anticipated impact on our analysis. A drop of one unit in $F$ decreases the average anticipated cost in the Full Information Scenario exactly by one.

Tables 4 and 5 show the following trends:

In the No Information Scenario there are two columns that show the expected value of the anticipated cost. We can see that the actual cost reached for ordering quantity $Q$ is consistently higher than the theoretical cost for ordering quantity $Q$ calculated by the inventory manager. This is the result of the fact that the inventory manager is not aware of the errors that are occurring and presents a theoretical cost whereas in reality errors occur and there is a need to take them into consideration when calculating the expected value of the anticipated cost, which is presented as the actual cost.

In the Full Information Scenario, the expected costs of purchasing quantity $Q$ relative to the other scenarios increases as a direct consequence of the periodic cost of Full Information F (in our simulation, the cost of the Full Information Scenario grew five units in comparison to the other scenarios). 
The lowest average anticipated cost for purchasing quantity $Q$ is found in the Informed Scenario and the Static Informed Scenario. In the Informed Scenario the inventory manager is aware that errors occur and in the Static Informed Scenario he is only aware of the expected value of the errors. In these scenarios, the manager reacts in order to minimize the cost.

The costs in the Informed Scenario and the Static Informed Scenario turn out identical even though the Static Informed Scenario does not take into account the distribution of errors, only the expected value without relating to the standard deviation. The reason for this may be rooted in the fact that the standard deviations of the item errors are very small and their influence on the cost is, hence, insignificant.

The largest quantity $Q$ purchased is reached in the Informed and Static Informed Scenarios.

The highest expected value of the anticipated cost for purchasing quantity $Q$ is found in the Full Information Scenario for the items whose cost for being held in inventory and cost of not having on hand is relatively lower than the other items.

When the holding cost $\mathrm{h}$ and the cost of not having the item on hand increase, the value of information in the different scenarios also grows. Information becomes a very valuable asset when the goal is to minimize discrepancies in the inventory records that lead to an increase in items not on hand or to a surplus. When these costs increase, costs that are created as a result of the discrepancies in the inventory also grow.

We can see that the paper reels (raw materials) have a higher cost of not being on hand $p$ and a surplus cost $h$ relative to the other items, and therefore, it is to the inventory manager's benefit to act according to the Full Information Scenario/policy. The reason for this lies in the fact that paying extra for holding inventory or paying for not having an item in demand in stock will be higher than paying a periodic cost for complete information. In these types of situations, accordingly, when the costs of lack and surplus are high, it is advisable to invest in developing infrastructures that will lead to having complete information.

When the average and standard deviation of the error sources increase, the value of information also increases and managing inventory efficiently is done through the Full Information Scenario. Full information enables the inventory manager to minimize these errors, which will minimize the expected value of the anticipated cost of purchasing quantity $Q$.

The maximum quantity $Q$ to purchase was found in the Informed and Static Informed Scenarios whereas the expected value of the anticipated cost in these scenarios was the lowest of the four scenarios.

When there are no errors and their distribution does not occur, we can see that the cost in all the scenarios is identical except for the cost in the Full Information Scenario, which has an additional component of fixed cost of additional information. This component constitutes the gap between the Full Information Scenario and the other three scenarios exactly, for this case.

When no errors occur, the expected value of the anticipated cost in the No Information, Informed and Static Informed Scenarios are exactly the same. The expected value of the anticipated cost in the Full Information Scenario is higher than in the other scenarios by precisely the amount of the periodic cost of additional information.

The simulation presents the value of information in the different scenarios for different sets of parameters. The various possibilities enable decision makers to select the scenario that best suits the parameters in their system. It is important to note that even though the calculations of this research were conducted for a limited range of parameter values, the calculations can be made for other parameter values using the equations presented in the model, and in so doing, calculate the value of information.

Looking at table 4 we can see the difference in cost per period when having no information (actual) to the different information scenarios. For example in plates there is a difference of more than 2,000 new Israeli shekels per period. This total cost is significant for the printing house.

\section{Conclusion}

In this research we examined the value of exact inventory information in supply chain management. It is known that discrepancies and gaps often appear between IT inventory entries and available-for-sale inventory-and this is one reason that organizations regularly carry out inventory reviews. There are three different cases that lead to discrepancies between the types of inventory records: shrinkage, misplacement and wrong scanning. According to Avrahami (2012), the scope of errors of the total consumption of an item is $1 \%, 0.008 \%$, and $0.008 \%$ for shrinkage, wrong scanning and misplacement, respectively. In our work we normalized the scope of errors of the total consumption to the scope of errors of the absolute gap that we found for each item, $98.43 \%, 0.79 \%$, and $0.79 \%$ for shrinkage, wrong scanning and misplacement, respectively. In order to assess the value of information we compared a system with conventional information (the No Information Scenario) to systems with different levels of information 
(Informed Scenario, Static Informed Scenario, and Full Information Scenario). From the management perspective, we determined that the optimal management in the Informed Scenario is a non-static base stock policy.

In order to understand the value of additional information and the need for investment in acquiring more information, we conducted a numerical study in the print industry in a printing house belonging to Yedioth Communication. Using the values of parameters that reflect real-world applications, we found that the average anticipated cost is lower when purchasing quantity $Q$ in the Informed and Static Informed Scenarios, according to which the inventory manager should manage the organization's inventory. When the cost of holding inventory $h$ and the cost of not having an item in stock $p$ increase, the value of information in the different scenarios also grows. The information becomes a very valuable asset in the attempt to reduce discrepancies in inventory entries that lead to an increase in items missing from the inventory or a surplus of items. When these costs rise, the costs that accrue as a result of inventory discrepancies also grow and, hence we see that the inventory in the Full Information Scenario is efficient and the investment in complete information is worthwhile. Likewise, we saw that when the average and standard deviation of the error sources grew, the value of information also increases and inventory was managed efficiently in the Full Information Scenario. The results clearly demonstrate that the greater part of the advantage of having additional information comes from knowing the anticipated values of the errors. Together with this, in most cases, but not in all, the investment in complete information is worthwhile, as we have shown.

\section{References}

[1] A. Atali, H. L. Lee and O. Özer, If the inventory manager knew: Value of visibility and RFID under imperfect inventory information, Working paper, Stanford University, California, 2006.

[2] A. Avrahami, The value of perfect and imperfect information in a multi- location inventory system, Ph.D. research thesis, Technion-Israel Institute of Technology, Israel, 2012.

[3] A. Avrahami, Y. T. Herer and R. Levi, Matching supply and demand: Delayed two-phase distribution at Yedioth Group - Models, algorithms, and information technology, working paper, Technion-Israel Institute of Technology, Israel, 2013.

[4] A. Avrahami, Y. T. Herer and A. Shtub, The paper reel supply Chain: An RFID enabled information rich approach, Journal of Theoretical and Applied Electronic Commerce Research, vol. 8, no. 2, pp. 1-15, 2013.

[5] A. Avrahami, A. Tzimerman, Y. T. Herer, and A. Shtub, The value of inventory accuracy in supply Chain management, working paper, 2014.

[6] S. Chang, D. Klabjan and T. Vossen, Optimal radio frequency identification deployment in a supply chain network, International Journal of Production Economics, vol. 125, no. 1, pp. 71-83, 2010.

[7] H. Hao-Chun Chuang, and R. Oliva, Inventory record inaccuracy: Causes and labor effects, Journal of Operations Management, vol. 39-40, pp. 63-78, 2015.

[8] N. DeHoratius and A. Raman, Inventory record inaccuracy: An empirical analysis, Management Science, vol. 54, no. 4, pp. 627-641, 2004.

[9] N. DeHoratius and Z. Ton, The role of execution in managing product availability in Retail Supply Chain Management (S. Agrawal and S. Smith, Eds.). Springer: NY, 2009, pp. 122-135.

[10] N. DeHoratius, A. J. Mersereau and L. Schrage, Retail inventory management when records are inaccurate, Manufacturing \& Services Operations Management, vol. 10, no. 2, pp. 257-277, 2005.

[11] E. Fleisch and C. Tellkamp, Ehe Impact of Inventory Inaccuracy on Retail Supply Chain Performance: A Simulation Study, International Journal of Production Economics, vol. 95, pp. 373-385, 2005

[12] M. Gaukler, W. Seifert and H. Hausman, Item-level RFID in the retail supply chain, Production and Operations Management, vol. 16, no. 1, pp. 65-76, 2007.

[13] E. S. Gel, N. Erkip and A. Thulaseedas, Analysis of simple inventory control systems with execution errors: Economic impact under correction opportunities, International Journal of Production Economics, vol. 125, pp. 153-166, 2010.

[14] D. L. Iglehart and R. C. Morey, Inventory systems with imperfect asset information, Management Science, vol 18, pp. B388-B394, 1972.

[15] J. R. Johnson, R. A. Leitch and J. Neter, haracteristics of errors in accounts receivable and inventory audits, The Accounting Review, vol. 56, no. 2, pp. 270-293, 1981.

[16] A. G. Kök, and K. H. Shang, Inspection and replenishment policies for systems with inventory record inaccuracy, Manufacturing \& Service Operations Management, vol. 9, no. 2, pp. 185-205, 2007.

[17] A. G. Kok and K. H. Shang, Evaluation of cycle-count policies for supply chains with inventory inaccuracy and implications on RFID investments, European Journal of Operational Research, vol. 237. No. 1, pp. 91-105, 2014.

[18] A. G. Kök, K. H. van Donselaar and T. van Woensel, A break-even analysis of RFID technology for inventory sensitive to shrinkage, International Journal of Production Economics, vol. 112, pp. 521-531, 2008.

[19] H. S. Lau, Simple formulas for the expected costs in the newsboy problem: An educational note, European Journal of Operational Research, vol. 100, pp. 557-561, 1996.

[20] H. L. Lee and O. Özer, Unlocking the value of RFID, Production and Operations Management, vol. 16, no. 1, pp. 40-64, 2007.

[21] H. L. Lee, K. C. So and C. s. Tang, The value of information sharing in a two-level supply chain, Management Science, vol. 46, no. 5, pp. 626-643, 2000. 
[22] Y. M. Lee, F. Cheng, and Y. T. Leung, Exploring the impact of RFID on supply chain dynamics, in Proceedings of the 36th Conference Winter Simulation, Washington, D.C., 2004, pp. 1145-1152.

[23] F. Liu, and Z. Miao, The application of RFID technology in production control in the discrete manufacturing industry, in Proceedings of the IEEE International Conference on Video and Signal Based Surveillance, Sidney, Australia, 2006, p. 68.

[24] A. Shtub, Enterprise Resource Planning (ERP): The Dynamics of Operations Management. Boston: Kluwer Academic Publishers, 1999.

[25] F. Tijun et al., Impact of RFID technology on supply chain decisions with inventory inaccuracies, International Journal of Production Economics, vol 159, pp. 117-125, 2015. 